\title{
REFLEXIONES SOBRE LA CRITICA DE BERGBOHM A LA DOCTRINA DEL DERECHO NATURAL ${ }^{2}$
}

Bergbohm es uno de los más puros positivistas jurídicos. Su crítica al derecho natural pretende ser total, exhaustiva, sin concesiones. No se limita al derecho natural clásico. Advirtiendo que, a pesar del triunfo de la escuela histórica, pervive toda una literatura iusnaturalista, tanto en Alemania como en el resto de Europa, que él mismo se encarga de inventariar minuciosamente,

I Justificación. Cuando yo comenzaba mi especialización filosófico-juxídica, advertí que no iría muy lejos si limitaba mi estudio a la literatura contemporánea, aún cuando abarcara sus tratados y monografías más completas, y que era necesario, más aún, imprescindible, conocer en sus fuentes las doctrinas de los grandes clásicos de la Filosofía del Derecho, tanto de la Antigüedad como del Medioevo y de la Edad moderna. A tiempo comprendi que sería un grave error estudiar una rama de la Filosofia como se estudia una ciencia positiva, en la que basta conocer su último estadio para dominarla porque en ella se ha efectuado ya una discriminación definitiva de lo verdadero y lo falso contenidos en su historia. Por el contrario, en la Filosofía, ya porque sus principios no dependen del descubrimiento de hechos empíricos, ya porque la índole de sus problemas no permite con frecuencia una solución definitiva, el conocimiento y la discusión del pensamiento anterior se hacen necesarios. Por eso puede decirse que mientras la historia de la ciencia, aun de la más reciente, es siempre historia "antigua", la historia de la Filosofia aun de Ia más lejana, es siempre historia "contemporánea".

Advertí también que, además de las fuentes y de su correspondiente literatura secundaria, había ciertas monografías de carácter histórico o crítico que también se habían convertido en clásicas por la profundidad y envergadura con que habian desarrollado su tema o por la influencia que habían irradiado.

Una de las obras de esta segunda categoría es la de Karl Bergbohm, Jurisprudenz und Rechtsphilosophie (Leipzig, Verlag Duncker und Humblod, 1892) que siempre ha pasado por ser la más completa Summa crítica contra la doctrina del derecho natural. No se podría desconocer la importancia de este escrito puesto que la Filosofia del Derecho fue, con raras excepciones, hasta la aparición de la escuela histórica, teoŕa del derecho natural, y aún continuaba cultivándose con esa tendencia contemporáneamente al desarrollo y al triunfo de la teoría enunciada por Savigny.

Pero el libro de Bergbohm no se encontraba en ninguna de nuestras bibliotecas públicas ni privadas, hacía muchísimos años que estaba agotado y era considerado una de las obras mås difíciles de hallar en el mercado de viejo. Así, durante treinta años me ví impedido de cumplir mi propósito, lo que tuvo como efecto abrir una lamentable laguna en mi formación de profesor y privarme del conocimiento de una serie de argumentos que debían contribuir a una visión más clara y a una solución mejor pensada de lo que es, sin duda, el problema central de la Filosofía juridica: el problema de la fundamentación de los contenidos correctos de un derecho positivo. Pero hoy el obstáculo ha sido vencido: la obra fue hallada en un anticuario de Alemania y desde hace ya un año forma parte de la biblioteca de nuestra Facultad de Derecho. No dudé entonces en estudiarla, y las reflexiones que me ha sugerido su examen son las que aquí doy a la publicidad. 
su ataque va dirigido sobre todo a ella. Y llega al extremo de escudrinar y descubrir abundantes residuos de iusnaturalismo en las mismas doctrinas de Savigny, Puchta y otros representantes del historcismo.

Su actitud es extrema: el derecho natural "debe ser abandonado por toda la Jurisprudencia y todo trabajo espiritual empleado en él es loca dilapidación" (pág. 479).

Estamos justamente en el punto histórico en que el dogmatismo ciencista se ha extendido de las ciencias naturales a las ciencias del espíritu. La Ciencia del derecho tiene un dogma fundamental: "sólo el derecho positivo es derecho y todo derecho positivo es derecho" (pág. 240 n. 4). En consecuencia, la doctrina del derecho natural es declarada expresamente una "herejía" contra ese dogma (id.) y el tal derecho es calificado como el "enemigo principal de toda ciencia jurídica sana" (pág. 233).

Ante esta lucha implacable, que adquiere el carácter de una cruzada y el tono de un fanatismo, habrá que preguntarse cuál es el motivo último y decisivo que la enciénde. Pero antes es necesario averiguar cómo define $\mathbf{B}$. el derecho natural y el derecho positivo.

$Y$ comprobamos que mientras formula una definición acabada, aunque muy discutible, del primero, el segundo queda en una determinación incompleta.

Esta desigualdad de tratamiento es consciente y querida. En el plan que B. se trazó, el primer volumen de su obra (el único que llegó a publicar) está destinado a liberar a la ciencia del derecho de los lazos del derecho natural y sólo posteriormente los volúmenes II y III estarían destinados a fijar la misión y el método de la ciencia y de la filosofía jurídicas y a completar con el examen del problema de la coacción el concepto de derecho positivo. Y la razón de esa preferencia radicaría en que la expulsión del falso saber es siempre una tarea previa a la búsqueda larga y difícil de la verdad (pág. 104 sig.).

Ya en este punto B. es víctima de una ilusión. Pues el conocimiento no es ni puede ser anterior al conocimiento de la verdad. Por el contrario, un error sólo es conocido como error desde la perspectiva que ofrece una verdad ya descubierta. Mientras esto no ocurra, el error será tenido por verdad. Este aserto vale tanto en el conocimiento intuitivo como en el discursivo. Sirva para el primer tipo el tan conocido ejemplo de la percepción del remo semisumergido. Si ésta ha sido la percepción originaria, no podré menos de tener por verdad que el remo forma un ángulo. Sólo cuando percepciones sucesivas visuales y sobre todo táctiles (a las cuales pueden unirse otras consideraciones) funden la verdad de que el remo es rectilíneo, descubriré que aquel primer juicio era erróneo. Parejamente, en el segundo tipo, el error del juicio "A es B" sólo puede resultar del previo conocimiento de la 
verdad de las premisas que lo hacen inconsecuente, por ejemplo, de que "ningún $B$ es $M$ " y de que "A es $M$ ".

Así, pues, si la doctrina del derecho natural es falsa, esto sólo podría establecerse sobre la base de ciertas verdades referentes al derecho y al hombre que la contradigan. De hecho B. no puede menos de proceder así, transgrediendo su propio método, pero la cuestión es si los asertos de que parte, han sido establecidos con el rigor y la claridad que permitan tenerlos por verdaderos.

Veamos, pues, los puntos de arranque para su amenazante crítica.

Define el derecho natural: "toda representación de un derecho que es independiente de institución (Satzung) humana" (pág. 13o sig.). Advertimos de inmediato que la fórmula no concuerda con ninguna de las definiciones de los propios iusnaturalistas; que no contiene ninguna determinación positiva del derecho natural, sino una puramente negativa: el de ser un derecho independiente de toda posición (=de todo acto de poner o instituir) humana. Esta definición, perfectamente pensada, permitirá a $\mathrm{B}$. incluir en su crítica no sólo a las doctrinas del derecho natural o racional, sino también a toda dirección a priori (pág. 104) que apele a una revelación, idea, sentimiento o sentido como principio del derecho (Cf. págs. 441 sigs.). Pero inmediatamente destaca como un carácter general de derecho natural así definido, el de presentarse como directivas vinculadoras, como normas que pretenden tener una significación obligatoria para la vida y la evolución del derecho (pág. 191), que sin base en las fuentes del derecho positivo, quieren tener cierta validez jurídica definida (pág. 132). Lo decisivo para $B$. no es de dónde viene, sino a dónde conduce ese derecho natural, esto es, a erigirse en principios vinculadores de la conducta y del derecho positivo mismo (págs. 136 y 135).

Por otro lado, al intentar definir el concepto del derecho positivo, después de decirnos que su género próximo consiste en ser algo normativo, una regla abstracta que se refiere a la organización de la vida común, pero limitada a la conducta exterior de los hombres entre sí y respecto a las cosas (pág. 81) B. pasa a tratar de su diferencia específica. Pero entonces se rehusa a enunciar una determinación precisa y clara y se limita a indicar que el problema radica en inquirir con qué fuerza o autoridad rigen las reglas de derecho como normas obligatorias y cómo reaccionan frente a un hecho que las contradice (pág. 82).

La definición del derecho positivo queda, así, incompleta. Lo cual significa nada menos que $B$. emprenderá toda su demoledora crítica del derecho natural con "mala conciencia", vistas sus pretensiones científicas, porque es en verdad una falla grandiosa proclamar ex-cathedra que "el dogma fundamental de la Ciencia del Derecho es que sólo el derecho positivo es derecho y que todo derecho positivo es derecho" (ver supra pág. 199) cuando no se ha 
podido ofrecer una definición acabada de tal concepto. $Y$ esa falla es una consecuencia de aquella ilusión metódica arriba señalada, de pensar que es posible determinar errores antes de descubrir verdades.

Sin embargo, a pesar del defecto de la proyectada definición del derecho positivo, es claro que B. atribuye a éste, como nota indiscutible, la obligatoriedad, el poder de vincular a la obediencia. Por ello dice al final de su obra: "ser derecho positivo y ser puesto en la existencia por un camino histórico como regla vinculadora, son uno y lo mismo" (pág. 546).

Resulta, asi, que B. destaca la misma determinación respecto a ambos derechos: la obligatoriedad o poder vinculador del derecho positivo es también una nota que el derecho natural pretende para sí. B. vuelve continuamente sobre esa vinculatoriedad y eficacia (ver págs. $141,367,397-99,496$ $\left.43^{8}, 439,44^{6}\right)$.

Ahora bien, esta coincidencia nos permite descubrir que la grave preocupación de B. es la posibilidad de un conflicto entre ambos derechos, y que el motivo hondo y poderoso que impulsa su extremosa crítica es el de salvaguardar la validez integral del derecho positivo de los embates del natural.

Por consiguiente, el supuesto inconmovible de todo el pensamiento de B. es que el derecho positivo posee esta validez, vinculatoriedad o carácter obligatorio.

$\mathrm{Y}$ aquí se abre un campo para la reflexión. Porque el filósofo no puede admitir sin más esa validez como un supuesto, sino que ha de preguntarse por los fundamentos en que se asienta y ensayar la solución pertinente. El problema es tan inevitable que el mismo B. se lo ha planteado, como hemos visto anteriormente, aunque rehusando dar la solución, sin advertir que ésta era necesaria desde su punto de vista para su propósito de destruir acabadamente la pretensión vinculatoria del derecho natural. $Y$ si lo hubiera examinado, se habría sorprendido al advertir que iría necesariamente a desembocar en aquel lugar del cual cabalmente pretendía alejarse.

Pero no adelantemos unas reflexiones que sólo cobrarán su plena sig. nificancia cuando examinemos en particular una de las críticas que ejecuta nuestro autor.

A una situación semejante llegamos, si consideramos otro de sus puntos de arranque. La Filosofía del Derecho, dice, tiene que ser científica, teórica y no práctica, esto es, suministrar un saber sobre la esencia del derecho ya existente, pero de ningún modo averiguar cómo se ha de formar el derecho, lo cual es tarea de la Crítica y de la Política (pág. 103).

Presenciamos aquí la transposición, habitual en todos los positivistas, de los postulados de las ciencias naturales a las ciencias del espíritu. Procediendo de esta suerte el positivismo cree dotar de un progreso metódico a las últimas y "elevarlas a la altura de verdaderas ciencias", como frecuentemente se decía, cuando en realidad les hace dar un paso atrás, porque des- 
conoce que las razones que hacen necesarios aquellos postulados en las ciencias naturales, no valen para el mundo del espíritu y muy especialmente para el derecho positivo. La naturaleza es el reino de la necesidad y por eso su ciencia no puede ser sino el conocimiento de lo que es y de sus leyes ineluctables. Esta ciencia es por esencia y primariamente teórica. Que si es posible una técnica para modificar sus procesos, ella no puede basarse sino sobre el conocimiento de aquellas leyes, que es preciso respetar y obedecer en todo caso. Pero si la baconiana "natura non dirigatur nisi parendo" fue presențada como una paradoja, es precisamente porque esa máxima no rige en el mundo del espíritu, donde lógicamente el obedecer supone el dirigir, pero donde el dirigir mismo, sea por medio de decisiones individuales o de reglas universales, puede tener sentidos y contenidos diversos y aún opuestos, ya que el espíritu es el reino de la libertad. La acción es siempre la realización entre todas las posibilidades que tiene el hombre cada vez. De ahí que surja para él el problema de lo que deba hacer (supuesto que no es indiferente que realice cualquiera de sus posibilidades) y la pretensión del derecho positivo de dar respuesta a ese problema, por lo menos en cierto sector de la praxis. Pero el contenido de un derecho positivo es también una posibilidad entre otras de la voluntad del hombre o del grupo de hombres que lo dicta. Por consiguiente, con respecto al derecho positivo se plantea una pregunta equivalente a la que se planteaba sobre la acción: la pregunta de cómo deba ser el contenido de ese derecho (supuesto que no sea indiferente que tenga cualquier contenido).

Todo esto nos conduce a advertir que cuando de praxis se trata, lo que tiene realmente importancia no es describir como ella es, sino determinar cómo debe ser, y que esto vale no sólo para la acción sino también para la regla positiva de la acción, puesto que ésta también depende de la voluntad. Hay, pues, dos problemas del deber ser que cabalgan el uno sobre el otro: el uno pregunta cómo debe ser la acción, el otro, cómo debe ser la regla de la acción.

Si ahora se objeta que el conocimiento de lo que debe ser no es científico, que las ciencias sólo se ocupan de lo que es, lo único que cabe responder es: tanto peor para la ciencia. En lugar de esto, el filósofo del derecho infectado de positivismo naturalista, prefiere abandonar el problema decisivo, so pretexto de no científico, cuando, según las reflexiones anteriores, lo que ha de reconocerse es que la consideración filosófica del derecho no puede tener como canon el esquema de una ciencia que sólo es adecuado para dominar una esfera del ente distinta de aquélla del espíritu. Y limitando el tema de la Filosofía del Derecho a la cuestión sobre la esencia formal del derecho, no se suprime el problema de su deber ser, sino que simplemente se lo traslada a otra disciplina, llámesela Critica o Política, y entonces será ésta la que adquirirá importancia de primer orden, la cual no se 
rebajará porque se le quiera negar el título de ciencia. Pero esa atribución del problema a otra disciplina perjudica a la ciencia y a la filosofía, porque impide o debilita la visión de las conexiones entre problemas planteados por un mismo objeto.

Asi, pues, los puntos de arranque de B. para la crítica del derecho natural, sometidos ellos mismos a crítica, están muy lejos de poder mantener el carácter de dogmas incontestables con que su autor pretende exhibirlos. Pero con nuestras consideraciones no hemos demostrado nada en favor del derecho natural. Queríamos poner en claro algo más importante que toda tesis, y es que el problema al cual pretende responder el derecho natural es un problema auténtico e inevitable.

Podemos examinar ahora la crítica en sí misma. B. la divide en dos grandes partes: en la primera somete a prueba la idea del derecho natural por su relación con el derecho positivo (págs. 367-407); en la segunda, por su relación con el concepto del derecho (págs. 408-478).

\section{El derecho natural frente al derecho positivo}

B. encara la crítica desde el punto de vista de la relación, porque si se admite que, además del derecho positivo, hay otro derecho, éste debe también vincular, $y$ entonces ambos presentarian su pretensión frente a las mismas relaciones humanas.

B. considera tres modos de concebir la relación.

A) Según los iusnaturalistas que él llama "moderados", el derecho natural sólo serviría para llenar las lagunas del orden jurídico positivo.

La crítica incide aquí sobre el supuesto. Este supuesto sería falso: el derecho positivo no tiene lagunas. Por consiguiente el derecho natural no tendría ocasión de realizar su ayuda (págs. 371 sigs.).

La cuestión es, pues, si el derecho positivo tiene o no lagunas.

Para demostrar su tesis, B. distingue dos casos. El primero es el de aquellos hechos que por su naturaleza podrían ser sometidos al derecho pero no lo han sido. Por ejemplo en nuestro país las asociaciones civiles, los sindicatos, o los menores sin protección antes de la ley de 1911.

Frente a esta ausencia, nuestro autor arguye que el derecho positivo nunca ha tenido por necesario regular la totalidad de la materia jurídica. Habría dos esferas: una de acciones y relaciones reguladas, y el resto que, aunque exija normación, cae en el espacio vacío de derecho. Ambas estarían separadas por una línea de demarcación arbitraria porque puede trasladarse de aquí para allá, sin que ningún jurista pueda fijar los puntos por donde ha de pasar. Aquí no habría ninguna laguna en el derecho, sino sólo 
en torno del derecho. El derecho regula determinada materia. Lo que queda fuera no debe ser angostado por normas, sino desenvolverse libremente (págs. 375-380).

Extraño modo de argüir, en el que se reconoce lo que se pretende negar, y en el que lo que se niega es sólo el concepto. Poco importa decir que aquí la laguna no es "en" el derecho sino "en torno" del derecho, cuando se califica a esa materia no regulada como "jurídica" y como exigiendo normación. ¿Qué diferencia hay entre llamar a ese hecho "laguna" o "espacio vacio" de derecho?

En realidad, toda la argumentación de B. se reduce a oponer a la exigencia de que las lagunas sean cubiertas con los principios del derecho natural, la de que lo que queda fuera de la materia regulada por el derecho "no debe ser angostado por normas, sino desenvolverse libremente" (pág. 380). Pero esto nos abre los ojos para ver algo más originario que el resolver la disputa sobre si tales hechos deben considerarse o no como lagunas. Y es que la determinación misma de la existencia de lagunas, tanto si se afirma como si se niega, sólo es posible sobre el supuesto de un principio a priori al derecho positivo mismo.

En efecto, la plenitud del derecho positivo, es decir, la negación de lagunas, se puede sostener si se supone el principio de que todo lo que no está regulado por el derecho está permitido. Pero este es un principio del derecho natural de los siglos xvir y xvmr, que concibe al estado de naturaleza (sea en sentido histórico, sea en sentido racional o ideal) como un estado de libertad absoluta, al cual el derecho positivo viene a poner límites, por lo que toda conducta que no ha sido limitada por el derecho puede continuar desenvolviéndose en libertad. Es innecesario citar aquí las pruebas literarias del carácter iusnaturalista del principio, porque son bien conocidas. Baste recordar que ha sido consignado - si bien referido exclusivamente a la ley- en la "Declaración" francesa de 1789 , art. 5: "Todo lo que no está prohibido por la ley no puede ser impedido, y nadie puede ser constreñido a hacer lo que ella no ordena", de donde ha pasado a tantas constituciones modernas. ${ }^{2}$

$\mathrm{Y}$ así hemos llegado a la paradojal conclusión de que el dogma de la plenitud del derecho positivo, propio del positivismo jurídico, requiere como supuesto un principio de derecho natural.

Y la contraprueba de que se trata de un principio suprapositivo y no de un elemento de la estructura lógica del derecho, como alguna vez se ha sostenido, reside en que la exclusión de toda laguna es posible también sobre el supuesto del principio inverso al antes enunciado, esto es, que todo lo que no está permitido o mandado por el derecho está prohibido. Aristóteles lo había expresado a propósito del suicidio: "la ley no permite el sui-

2 Ver por ejemplo, Constitución del Uruguay, art. 1o, inciso 2. 
cidio y lo que ella no permite lo prohibe". ${ }^{3}$ Por más que este criterio pueda en su generalidad parecer chocante y haya dado lugar a muchas críticas, interpretaciones e incluso correcciones del texto aristotélico, no es de ninguna manera absurdo. Justamente él rige en el derecho público, pues ningún órgano del Estado puede realizar otros actos que aquellos que las leyes autorizan. Partiendo de él, pues, también pueden negarse las lagunas del derecho público. El principio así limitado no es incompatible con el anterior en un mismo orden jurídico, sino, por el contrario, su complemento lógico. Pues una garantía de que los ciudadanos sean libres de hacer todo lo que la ley no prohibe, es que los órganos del Estado no puedan hacer más que lo que la ley les permite.

Pero para el problema que nos ocupa estas distinciones son indiferentes. Lo evidente es que las lagunas del derecho sólo pueden negarse bajo el supuesto de un principio a priori, sea éste el de que todo lo que no está prohibido está permitido o el de que todo lo que no está permitido está prohibido. Es claro que en este caso hay que concluir que el derecho natural no tendrá ocasión de prestar su ayuda. Pero ello no es un argumento contra él, como cree B., sino una aplicación de un principio suyo.

Pero la tesis contraria a la que hasta ahora hemos examinado, la tesis de que hay lagunas en torno del derecho positivo, también sólo es posible sobre el supuesto de un principio a priori al derecho positivo mismo. Sólo que este principio no es ya el de la libertad sino justamente otro que limita a éste. La idea del bien común, de la justicia, de la seguridad, etc., exigen que determinadas relaciones o situaciones humanas no queden abandonadas a sí mismas o al libre ejercicio de la voluntad de los individuos, sino que estén reguladas de determinado modo. $Y$ es cuando el Derecho positivo no contiene esa regulación cuando puede hablarse de "lagunas". Pues sólo puede comprobarse la no existencia de una regulación por referencia a un principio que exija su existencia.

De aquí se sigue que el traslado de la línea de demarcación entre la materia regulada positivamente y el "espacio vacío de derecho" no es de ninguna manera arbitrario, como cree B. Desde luego que no es un problema jurídico (en esto concuerdo con B.) en el sentido de que no es ni puede ser el derecho positivo el que dé el criterio para resolver si su regulación debe ser extendida a otros terrenos o no. Pero es un problema que necesariamente sc plantea al jurista y que éste tiene que resolver a partir de criterios suprajurídicos, como ha debido hacerlo con la materia ya regulada. El traslado de aquella línea de demarcación tiene que obedecer y de hecho ha obedecido siempre a uno de estos dos motivos: o bien el legislador entiende que, con referencia a materia social no regulada positivamente, debe predominar sobre la libertad alguno de los otros principios

3 Aristot. NE, V, 1138 a 6. 
(justicia, bien común, etc.), o bien han surgido nuevas relaciones o situaciones sociales que no pueden subsumirse bajo los conceptos del derecho positivo vigente. $Y$ sería sólo cuando existiendo uno de esos motivos, el legislador omitiera la regulación positiva, cuando habría lugar para la aplicación de los principios del derecho natural. Si esto es legítimo o no, es secundario frente al resultado que por el momento hemos obtenido: que tanto la tesis que niega las lagunas en torno del derecho positivo como la que las afirma se basan en principios a priori al derecho positivo, esto es, en principios de derecho natural en el sentido amplio que le ha concedido $B$.

Por consiguiente, la negación de las lagunas no consigue matar por inanición al derecho natural.

El segundo caso de lagunas considerado por $B$. es aquel en que se buscan en el derecho positivo soluciones para problemas que pertenecen a las relaciones humanas incluidas en la esfera de ese derecho, pero respecto a las cuales ésta calla. Son las llamadas "lagunas" en sentido estricto. Pero nuestro autor rechaza también éstas. Pues arguye que si realmente el derecho calla, el problema no es jurídico. Si después de emplear todos los medios de conocimiento, resultara que no hay una decisión del derecho, habría que declarar no jurídico el pretendido problema, puesto que caería en el ya indicado espacio jurídicamente vacío. Donde esto no se puede admitir entonces tendrá 4 que hallarse una decisión en el derecho positivo que se refiera a la supuesta laguna. Es ante esta tarea ante la que se halla el juez. Puede ser difícil encontrar la decisión, pero ella existe. La laguna nunca está en el derecho sino en el saber del que lo investiga (pág. 381 sig.). Reconoce que la ley tiene lagunas, pero distingue entre ley y derecho. La distinción, no muy clara, parece consistir, según las manifestaciones de $\mathbf{B}$. (pág. $3^{82}$ sig.) en que la ley suministra al individuo un saber, pensamientos jurídicos, mientras que el derecho es la totalidad del sistema jurídico, que comprende todas las fuentes. Éste, por pequeña que sea la materia regulada, nunca tendría lagunas, porque su fecundidad interna, su fuerza lógica de expansión cubriría en todo momento la necesidad de juicios jurídicos.

Pero respecto a esta segunda clase de lagunas la argumentación de B. es menos válida aún que respecto a la primera. No podemos detenernos aquí detalladamente en el problema. Hoy es admitido por muchos este tipo de lagunas ${ }^{5} \mathrm{y}$, en verdad, un examen objetivo no puede negarlo. Sólo avanzaremos aquí algunas consideraciones. De "lagunas" sólo tiene sentido hablar respecto a las disposiciones generales de derecho, esto es, respecto a las

4 El subrayado es nuestro.

5 Véase por todos: E. Zitelmann, Lagunas en el derecho y Kantorowicz, La lucha por la ciencia del derecho, en el vol: Savigny, Kirchmann, etc. La ciencia del Derecho, Losada, 1949 . 
normas, pues el problema aparece cabalmente antes y a propósito de una decisión a tomar ante una situación concreta. Admitido esto, la distinción entre ley y derecho no suministra la solución, si "derecho" ha de entenderse siempre, en el espíritu de B., como derecho positivo. Pues, aparte de la legislación, no hay más fuente de normas que el derecho consuetudinario y éste puede ser tan lagunoso como aquélla. $Y$ en países como el Uruguay, en donde la costumbre sólo vale en cuanto la ley se remite a ella (C. Civil art. 9) la cuestión prácticamente se localiza en las lagunas de la ley.

Apelar a la "fecundidad" o a la "fuerza lógica expansiva" del derecho sólo puede entenderse, en un sentido no metafórico, como subsunción de lo específico en lo genérico, en cuyo caso, desde luego, no hay lagunas, o como razonamiento por analogia, el cual supone las lagunas. Ahora bien, donde las lagunas pueden ser complementadas por la analogía, pueden serlo también por el derecho natural. La circunstancia de que un determinado derecho positivo prescriba al juez fallar sólo "por el fundamento de leyes análogas", no obsta a aquella posibilidad de principio, que es lo que niega B.

Pero si agotadas las fuentes y procedimientos lógicos resultara que no se halla una decisión del derecho, de ninguna manera podría decirse, como quiere B., que entonces el pretendido problema no es jurídico porque cae en el espacio jurídicamente vacío. Si en el primer grupo de casos vimos que era discutible la tesis de las lagunas porque la solución dependía del principio que se tomara como supuesto, en este segundo grupo su existencia es innegable porque el mismo derecho positivo, por decirlo así, las testimonia. Pocos ejemplos bastarán para evidenciarlo. Supongamos que una constitución establece que los titulares de un determinado poder del Estado serán designados por elecciones generales, pero omite establecer el tiempo o el modo, p. ej. si el voto será público o secreto, oral o escrito, etc. O bien: una norma constitucional puede ordenar al legislador la creación de otras normas, sin que éste haya cumplido con tal exigencia, como ocurre hasta hoy con los art. 55 (distribución del trabajo) y 57 ( ejercicio del derecho de huelga) de la Constitución del Uruguay. Es una burda falacia sostener que en esos casos hay simplemente un espacio jurídicamente vacío y no una auténtica laguna, cuando ésta se halla denunciada por la propia ley, cuyos contenidos están "llamando" a otros contenidos que deben complementar a los primeros. Pero hay más: los conceptos jurídicos tienen una generalidad limitada, porque el legislador ha tenido a la vista aquellos tipos de comportamiento o situaciones que se repiten, o que, por lo menos, le eran conocidos. Pero la realidad social siempre es más rica en posibilidades que la imaginación del legislador, y un hombre puede hallar con frecuencia modos de actuar que escapen a los conceptos que el derecho ha empleado. Por lo demás, a menudo éstos no han sido definidos por la ley. Por eso todo derecho requiere interpretación. Por ejemplo, el art. $26_{3}$ del 
C. Penal uruguayo castiga el "segundo matrimonio válido". Pero una persona casada podría contraer dos matrimonios ulteriores el mismo día y hora, uno personalmente y otro por representante. Otro ejemplo: todos los wagones del Metro de París tienen un letrero que dice: "está prohibido escupir" mientras que los wagones de la Ligne de Sceaux dicen: "está prohibido escupir en el piso". De acuerdo con la fórmula estricta de esos preceptos, el que viaja en los primeros no podría escupir ni en el W. C., mientras que el pasajero de los segundos podrá hacerlo sobre los cristales o las portezuelas. Es por ello que Kantorowicz pudo decir que en la ley las lagunas no se encuentran casualmente sino que en ella "hay tantas lagunas como palabras". 6

Por consiguiente, si es incontestable la existencia de lagunas intrajuridicas, cae otra vez el argumento de $\mathbf{B}$.

Para no olvidar ninguna posibilidad, nuestro autor considera, al margen de las lagunas, la existencia de conflictos surgidos por una obligación jurídico-positiva que pudiera dejar un resquicio abierto al arbitraje del derecho natural. Pero B. le niega esta última esperanza (págs. 39o sigs). Para fundar su negativa distingue dos casos:

x) La oposición puede consistir en el contenido normativo de varias proposiciones jurídicas. Entonces nuestro autor apela a su distinción anterior entre el Derecho y sus testimonios o fuentes. Admite que éstos pueden presentar diversos pareceres. "Pero es imposible -agrega- que el Derecho pueda suministrar dos soluciones incompatibles entre sí. El Derecho no es un agregado de leyes que contengan antinomias... sino un sistema armónico de disposiciones imperativas". Las antinomias sólo existirían en la cabeza del intérprete.

2) La colisión puede ocurrir entre motivos de obligación de naturaleza diferente: jurídico y moral o jurídico y religioso. Pero estos conflictos no pueden ser superados de modo jurídico ni filosófico-jurídico. Si se solucionan, habrá sido sin cooperación del derecho, y si no se solucionan, ningún derecho ideal puede suministrar la decisión, sino sólo, bajo apariencia de un principio jurídico, recomendar la toma de posición a favor de uno de los poderes en lucha. Así, en la rivalidad de Estado e Iglesia en el Derecho matrimonial. Y si se trata de un conflicto entre el Derecho y la moral o la religión, al que se halla en él no le queda otra alternativa que ser infiel a su convicción o sufrir el martirio.

Admitamos la argumentación de B. en el segundo caso, si bien ella es susceptible de algunas precisiones. Pero en el primer caso salta a la vista que nuestro autor, para poder mantener su posición anti-iusnaturalista, tiene que apelar a una construcción que, por cierto, no concuerda con los cánones del positivismo. Sin duda, ahora se aclara algo su distinción ante-

6 Op. cit., pág. 337 . 
rior entre el Derecho y la ley. El Derecho no sería la suma de las fuentes jurídicas sino un sistema por esencia coherente y que se hallaría más allá de las fuentes, puesto que se le concede a éstas el simple carácter de "testimonios". Pero ¿dónde puede hallarse ese sistema de "disposiciones imperativas" si no es en el contenido mismo de las leyes o de las costumbres? Y si no se hallan aquí, ¿no se está admitiendo, con otras palabras, que el Derecho tiene una existencia trascendente a sus propias fuentes? ¿No significa esto una concesión a contre-coeur al iusnaturalismo, en el sentido amplio en que lo entiende el autor, un residuo de Derecho natural, necesario para armonizar las contradicciones de las leyes, que, por otra parte, él reconoce paladinamente? Pues sería un procedimiento ineficaz querer reducir la tarea de armonización al sólo empleo de la lógica, porque ninguna lógica puede armonizar lo contradictorio.

Se percibe, así, el truco del positivismo jurídico: para anular toda intromisión del Derecho natural necesita sostener a toda costa no sólo que el Derecho positivo no tiene lagunas sino también que no puede ser contradictorio, y como las lagunas y las contradicciones no se pueden negar, tiene que atribuir al Derecho un ser más allá de las propias fuentes jurídicas. Pero este truco se convierte en una mangana ("pial") en que él mismo se enreda, porque si ese Derecho no coincide con sus fuentes ni tampoco quiere ser Derecho natural, es un fantasma, una ficción, por más que B. se empeñe en negarlo (pág. $3^{88)} .^{7}$ Luego, para cerrar toda salida, se declara que las antinomias como las lagunas sólo existen en la cabeza de los intérpretes. Pero es gratuito suponer que en general la cabeza de los que interpretan el Derecho haya de ser más débil que la cabeza de los que lo hacen. Más plausible es la presunción, inversa porque los primeros son siempre juristas de profesión, mientras que los segundos con frecuencia no lo son. Hoy tenemos una compilación impresionante sobre las incoherencias a que puede llegar el Derecho positivo en el famoso libro de Ripert, Le déclin du droit. $\mathrm{Y}$ para no agregar más que un caso, la legislación uruguaya posee el specimen de una ley, uno de cuyos artículos suprimía a otros artículos anteriores de la misma ley. ${ }^{8}$ Ejemplo, probablemente único en el mundo, de dis-

7 La distinción entre derecho y ley, ambos en sentido objetivo, se encuentra en algunos autores de la Edad moderna con un sentido claro y preciso: "derecho" significa justamente derecho natural y "ley", derecho positivo. Así Bodin identifica el derecho con la equidad, con lo que a la conciencia se presenta como justo, y a la ley, con el mandato, pues "la ley no es otra cosa que el mandato del soberano que ejercita su poder" (Rep. 1,8); en el mismo sentido, más de dos siglos después, Portalis, para quien "el derecho es la razón universal... fundada en la naturaleza misma de las cosas. Las leyes son... el derecho reducido a reglas positivas... El derecho es moralmente obligatorio... las leyes mandan" (Fernet. Recueil des travaux préparatoires du C. C., II, pág. 3). Es probable que la distinción del positivismo jurídico entre ley y derecho se haya inspirado en aquellas o en otras paralelas, pero en $B$. ha perdido su precisión.

8 Ley No 12.079 de 11 de diciembre de 1953, art. 55 . 
posiciones jurídicas que fueron derogadas en el mismo instante en que fueron promulgadas.

Cabe hacer, ahora, una observación de carácter general. Los iusnaturalistas que B. llama "moderados" son todos (Ahrens, Oudot, etc.) posteriores a las grandes codificaciones del siglo xvir (Landrecht prusiano) y del xIx (C. Civil francés y austriaco). Pero B. no advierte que la modestia de sus pretensiones es sólo aparente. Si limitaban el Derecho natural a complementar las lagunas o a resolver las contradicciones del Derecho positivo era porque aquellas grandes codificaciones se habian inspirado cabalmente en principios del Derecho natural. ${ }^{\text {Eran }}$ consecuentes, pues, al pedir que las lagunas se llenaran con los principios de éste. Si no hubieran pensado sobre esta base, habria que atribuirles una pretensión tan incongruente que resulta inverosímil: la pretensión de completar un Derecho con otro cuyos principios no tuvieran ningún parentesco con el primero. El positivismo jurídico es el olvido de la génesis del Derecho positivo actual.

B) Un segundo modo de encarar la ręlación entre ambos derechos es el de muchos autores clásicos según los cuales el Derecho natural consistirá sólo en puros principios y el Derecho positivo serviría para detallarlo y concretarlo con fines a su aplicación.

La crítica de B. es aquí paralela al modo anterior. Sostiene que el supuesto de la relación es lógicamente imposible. Pues el que reconoce un Derecho no positivo tiene necesariamente que aceptar un sistema ideal completo para todas las relaciones exteriores concebibles, de modo que cesaría toda posibilidad de intervención del Derecho positivo (págs. 393-96). Se trata del mismo argumento sub A) aplicado ahora al Derecho natural. Allí sostenía: el Derecho positivo no tiene lagunas, luego no hay lugar para una aplicación del Derecho natural. Ahora sostiene: a la idea del Derecho natural pertenece necesariamente el no tener lagunas, luego, supuesto tal Derecho, no habría lugar para su complementación por parte del Derecho positivo. Para demostrar su tesis B. hace dos hipótesis I) si se supone que alguien ha pronunciado respecto a un solo hecho que hay un Derecho natural, nada le impediría pensar otras acciones o estados regidos también por preceptos de ese Derecho. Y así se irla formando un instituto tras otro de suerte que basta que alguien se forme un solo concepto de acuerdo al método iusnaturalista para que sea conducido necesariamente a un sistema completo de Derecho ideal; 2) si alguien estatuye un Derecho natural en general, ten. dría que detallarlo en preceptos para las distintas ramas del Derecho. Y así se llegaría al mismo resultado que en la hipótesis anterior. La razón, que es inagotable para el iusnaturalismo, no podría fracasar en determinado

9 Svarez (Schwarz) era de la escuela de Wolff, Portalis era también iusnaturalista, y von Zeiller, de la escuela de Kant. Véase sobre esto el notable libro de Wieacker, Historia del derecho privado en la Edad moderna, Aguilar, 1957, págs. 294 sig.; 308 sig. 
punto. Por lo tanto, el Derecho natural no puede admitir ningún espacio jurídicamente vacío $y$, de consiguiente, no necesitará el complemento de - ningún Derecho positivo, excepto para la determinación de números, cuotas, plazos, etc., que siempre será arbitraria.

Examinaremos la objeción primero desde el punto de vista lógico y luego desde el punto de vista histórico.

B. está en un error al sostener en general que a un sistema de normas completo no le puede ser agregado otro sistema de normas para concretarlo. Eso dependerá del grado de generalidad de los conceptos contenidos en ambos sistemas. Si el grado de generalidad es el mismo, es claro que ambos serán incompatibles, pero si el grado de generalidad difiere en uno y en otro, pueden ser perfectamente complementarios. El ejemplo de las clasificaciones zoológicas iluminará con toda claridad. lo que decimos. La división de los vertebrados en peces, batracios, ànfibios, aves y mamíferos es completa (por lo menos empíricamente, ya que no se conoce ningún vertebrado que no esté comprendido en alguna de esas cinco clases) y sin embargo, se le pueden añadir y de hecho se le han añadido otras divisiones en órdenes, familias, especies, etc. que complementan y detallan a la primera. ¿Por qué es ello posible? Justamente porque cada una de ellas está formada por conceptos de un grado de generalidad cada vez menor y que, sin embargo, contiene determinaciones nuevas que no pertenecen a los conceptos de mayor generalidad. Mutatis mutandis puede ocurrir lo mismo entre dos sistemas de normas. Si suponemos que el Derecho natural consta de un sistema completo de normas muy generales (por ejemplo, que toda persona debe ser libre, que los padres deben cuidar de la prole, que el trabajo es un deber, que los pactos deben ser observados de buena fe, que todo delito merece una pena, etc.) es posible que el Derecho positivo detalle y concrete ese sistema en otro de generalidad menor y de mayor determinación (por ejemplo, qué actos pueden realizar los padres con las personas y los bienes de sus hijos, qué pena ha de merecer cada especie de delito, etc.). Se percibe así claramente cómo un sistema de normas sin lagunas puede ser complementado por otro sistema de normas; que puede ser completo sin por ello ser cerrado, pues quedan abiertos otros sistemas cuyo grado de generalidad sea diferente al suyo.

Por otra parte, B. parece suponer, según se desprende de su argumentación, que el iusnaturalista está en posesión de un método que le permite elaborar el Derecho natural en un sistema de preceptos de concretidad ilimitada, como si se tratara de una operación que pudiera llevarse a cabo con los solos medios de la lógica. Olvida que el Derecho natural se basa en la naturaleza de las cosas en general y del hombre en especial y que por consiguiente, la tarea del iusnaturalista no puede consistir en elaborarlo sino en descubrirlo o en formular conceptualmente lo que la evidencia nos presenta. Estrictamente, aquellos principios que no se basen en la naturaleza no pertenecen 
al Derecho natural, aunque sean conclusiones lógicas o determinaciones de aquéllos. En todo caso, nunca estas últimas, porque contienen supuestos de hecho y consecuencias que no están contenidos en los principios. En este punto la crítica de B. parece plausible porque, dada la enorme amplitud de su definición del Derecho natural, recayendo sobre las doctrinas racionalistas, arrastra también a todas las otras doctrinas iusnaturalistas.

Es indispensable, pues, luego de examinada la crítica desde el punto de vista lógico, echar un vistazo a las principales teorías del Derecho natural, tales como efectivamente han aparecido en la historia, para determinar si la crítica de B. es pertinente. El problema, entonces, tiene que ser planteado así: ¿sostuvieron las grandes teorías iusnaturalistas que el Derecho natural es un sistema ideal completo, es decir, un conjunto de normas que abarque todas las relaciones humanas externas concebibles?

Si consideramos las grandes doctrinas desde Santo Tomás hasta Chr. Wolff, observaremos un cambio notable en sus pretensiones. Para Santo Tomás la lex naturalis se compone de un número limitado de principios. Son principios de la razón práctica que desempeñan una función paralela a los principios del conocimiento respecto a la razón especulativa. ${ }^{\text {po }}$ Se trata de un grupo de "preceptos comunísimos" conocidos de todos y de sus más próximas conclusiones. ${ }^{11}$ Todos los otros preceptos del Derecho pertenecen al Derecho positivo, el cual puede derivarlos del natural de dos modos: I) como conclusiones de los principios, por ejemplo, del principio de que no debe dañarse a nadie, se deriva como conclusión que no se debe matar; 2) como nuevas determinaciones de los principios, por ejemplo, del principio de que todo delito debe ser castigado, la determinación concreta de la pena para el homicidio. Y Santo Tomás agrega expresamente que, si bien la validez de las conclusiones deriva en parte de la ley natural, la validez de las determinaciones deriva exclusivamente de la legislación humana. ${ }^{12}$

Una primera extensión del contenido de la lex naturalis la produjo Suárez al sostener que a ella pertenecen no sólo las normas supremas evidentes a todo hombre y otras menos generales pero aún iluminadoras sino también todas las conclusiones que de aquéllas derivan, ${ }^{13}$ y que Santo Tomás atribuía en parte a Derecho positivo. Por consiguiente, en la doctrina de Suárez hay todavía, a pesar de esa inclusión, un margen enorme para los preceptos propios de la ley positiva. Ya Soto había aducido como una de las razones que hacen necesaria la lex humana la multiplicidad de cosas, casos y negocios. ${ }^{14}$

Muchos iusnaturalistas tanto católicos como protestantes, continuadores $10 S$. T. I, II, 94, 2.

11 Id. id. $94,6$.

12 Id. id. 95, 2.

13 De leg. II, 7, 3 y 4.

14 De just. et jure. I, 5 . 
de Suárez y de Melanchton, se mantuvieron en la actitud prudente. de la tradición. 15 Y una actitud análoga, aunque obedeciendo a otros fundamentos y a otros fines, la adoptó Hobbes, para el cual la lex naturalis consta sólo de unos veinte preceptos.

En cambio, Grocio, incitado por aquella inclusión de las conclusiones hechas por Suárez, había de dar un paso decisivo en la constitución del Derecho natural como sistema. En su obra no sólo avanza que la "jurisprudencia natural" forma un "cuerpo", sino que enuncia una serie grande de preceptos de Derecho natural en todas las partes del Derecho privado: personas, cosas, sucesiones y obligaciones; prescripciones fijas sobre el matrimonio, sucesión intestada, modos de adquirir, de ejercer y de perder la propiedad, etc. ${ }^{16}$

Esto condujo a la creencia errónea de los siglos xvir y xvir en un Derecho natural material universal y constante, que contiene preceptos acabados para todas las relaciones concretas de la vida.

Aunque Pufendorf se acerca a esa concepción, no debe ser considerado un neto representante de ella. Es cierto que él afirmó un principio supremo del cual pudieran derivarse consecuentemente todos los preceptos de Derecho natural formando un sistema de partes entre sf coherentes, pero nunca sostuvo que ese sistema abarcara todas las relaciones humanas. Por el contrario, siguiendo la doctrina de Grocio de que el Derecho natural no sólo manda y prohibe sino que también permite, ${ }^{17}$ destaca que el Derecho natural calla en muchas cosas, lo que da lugar a que el soberano pueda regular muchas acciones de tal o cual modo de acuerdo a las necesidades o a las circuns. tancias. Pero el Derecho natural obliga a la observancia de esas leyes positivas, las cuales en virtud de ese precepto del Derecho natural se convierten ellas mismas en lo que él llama "jus naturae hypotheticum".18 Sólo por esta transposición del Derecho positivo en Derecho natural puede decirse que Pufendorf instaura un sistema completo de Derecho natural, en contraste con la prudente parsimonia de los teóricos antiguos y escolásticos.

Fue Christian Wolff el que sostuvo de modo expreso que todas las acciones humanas están reguladas por el Derecho natural, de suerte que adquiere el carácter de un sistema cerrado y unitario que abarca tanto la vida privada como la pública, tanto a los individuos como a los estados y se extiende incluso a los gestos y a los ademanes. Y Wolff desarrolló y expuso en detalle todo ese sistema. ${ }^{10}$

15 Véase una lista en Sauter J. Die philosophischen Grundlagen des Naturrechts, Wien, 1932, pág. 99 sig.

16 De jure belli ac pacis. Proleg. 31. Cf. Llambias de, Azevedo J. La Filosofía del derecho de $H$. Grocio. Montevideo, 1935, pág. 49.

17 Cf. Llambías de Azevedo, op. cit., pág. 45.

18 De jure nat. et gent. II, 3, 24; De off., hom. et civ. Praef, 3; II, 12, 8.

19 No he podido consultar las obras de Wolff. El texto resume el análisis hecho por J. Sauter, op. cit., págs. 188 y 190 sig. 
El vistazo que hemos echado muestra así, claramente, que hay una marcada diferencia entre las doctrinas escolásticas (continuadoras en éste como en tantos otros problemas de las greco-latinas) que enuncian un número relativamente pequeño de principios de Derecho natural, y las doctrinas de la Edad Moderna que, a partir de Grocio, van acentuando la tendencia a ampliar el número de aquellos principios hasta llegar con Wolff a la exposición de un verdadero código de Derecho natural.

La crítica de $B$. es en el aspecto histórico incorrecta, no tanto porque involucra indistintamente a ambos grupos de doctrinas, sino más bien porque pretende extraer consecuencias lógicas que las doctrinas del primer grupo expresamente rehusan. Y esto, aparte de que, como antes hemos visto, lógicamente puede no haber lugar para tales consecuencias. En realidad B. ignora a la doctrina de los escolásticos hasta el siglo xvi. Al único que menciona es a Santo Tomás y las referencias que hace (pág. 26o, n. 37) demuestran que lo conocía muy superficialmente.

Por otra parte, ninguno de los grandes iusnaturalistas ha sostenido que el Derecho natural hiciera superfluo al positivo. Por el contrario, todos sostienen que el Derecho positivo es necesario no sólo en cuanto añade algo al natural, sino también en cuanto solamente lo repite, porque mediante la coacción puede obligar a la voluntad con una eficacia de que carece el na- tural. Bastará con citar aquí a Wolff, el que por sostener que el Derecho natural regula todas las acciones del hombre, parecería que debiera concluir la autosuficiencia de éste. Un hombre razonable, dice, no necesitaría ninguna otra vinculatoriedad para realizar lo bueno. $\mathrm{Y}$ sin embargo, sostiene, por otro lado, que hay diversas causas que hacen que no basten la ley natural y su vinculatoriedad. La debilidad natural conduce a que los individuos no cumplan sus deberes y otras causas impiden el ejercicio de los deberes y los derechos. Por estas razones es necesario agregar a la vinculatoriedad interna, otra nueva, una vinculatoriedad exterior o civil, justamente por medio de las leyes positivas, que están provistas de coacción. ${ }^{20}$

C) Un tercer modo de relacionar ambos derechos es considerar al Derecho natural como rasero crítico o como fundamento del positivo.

Pero por los supuestos y consecuencias que implica, B. objeta que el Derecho ideal no puede tener esas funciones, y que no es más que una ficción vacía con tendencias de agitación.

I) Si se trata del Derecho natural como rasero crítico del positivo, los iusnaturalistas no ven que hay una diferencia considerable entre la vinculatoriedad formal del Derecho positivo y su bondad material, entre el hecho de su existencia y su valor o desvalor. Según B., hay que afirmar incondicionalmente la validez del Derecho positivo, a menos que tenga fallas constitucionales, en cuyo caso no la tiene. La virtud del jurista radica en sus-

20 Ver Sauter J., op. cit., pág. 190 sig. 
traerse al influjo de convicciones o deseos del corazón y esperar a que llegue el momento de la reforma del Derecho. Pero el iusnaturalista no es capaz de pensar que un Derecho, a pesar de ser malo es Derecho, sino que entiende que si no concuerda con su rasero, ya no es Derecho.

El error consistiría en querer hallar un Derecho por encima del Derecho, en tanto que toda crítica del Derecho toma su criterio de otra instancia exterior al Derecho. De lo contrario, Ia consecuencia sería que a la parte criticada se le quitaría su validez, lo cual, a su vez, sería contra el supuesto originario, esto es, que esa parte es también Derecho. (pp. 397-99).

2) Si el Derecho no positivo se concibe como fundamento juridico del positivo, sería más oscuro aún. La justificación a base de Derecho natural, racional, etc., no suministra, según B., ninguna explicación. Si el Derecho no puede hallar apoyo satisfactorio en puros hechos, habria que investigar el fundamento también más allá del propio Derecho natural. El autor sostiene que el Derecho positivo tiene su justificación ya en su existencia. Esto no significa que su pretensión a seguir rigiendo no pueda ser negada por mil razones pero no por una razón jurídica. No tiene sentido querer confirmar el Derecho positivo con el Derecho natural porque lo que ya es Derecho no necesita ninguna confirmación ni legitimación por medio de un Derecho superior. ¿No sería más sencillo, en lugar de apelar a un Derecho racional, decir que el Derecho positivo descansa directamente en la razón?

El fin que se propone el iusnaturalismo es poder negar la cualidad juridica a una parte considerada desfavorable del Derecho positivo. En realidad se emplea el Derecho natural, sea como rasero, sea como fundamento, para sustraer algo al Derecho positivo. Pues ese derecho superior es inútil cuando concuerda con el positivo. Sólo es importante cuando esta o aquella parte del positivo no concuerda con aquél (págs. 399-402).

Haremos ante todo un examen común a las objeciones que el autor presenta separadamente para los casos 1) y 2), porque en realidad obedecen a un pensamiento también común, que puede reducirse a los siguientes enunciados:

El pretendido Derecho natural no es Derecho. Es una ficción. Se admite un criterio extrajurídico del Derecho, pero de ningún modo que este criterio sea, a su vez, jurídico, pues entonces quitaría su validez al Derecho positivo (en todo o en parte).

Ahora bien, éste posee una validez o vinculatoriedad incondicionada. Esa validez es puramente formal, subordinada sólo a las normas constitucionales, pero es independiente del valor de sus contenidos.

$\mathrm{Su}$ justificación descansa en puros hechos, en su mera existencia, pues es más que un pensamiento en la conciencia: es una "energía activa" (cfr. pág. 405), una realidad contra la que el hombre chocará siempre, aunque 
en el pensamiento la declare nula. Por eso no necesita ninguna confirmación por un Derecho superior.

Por consiguiente, el Derecho natural es superfluo cuando concuerda con el positivo y en realidad sólo se lo utiliza para negar la vinculatoriedad, en todo o en parte, del positivo. Pero esto conduciría a la destrucción de todo orden jurídico, a la anarquía (cfr. pág. 407).

Evidentemente, toda la argumentación de B. gira en torno de la cuestión de la vinculatoriedad. En su esencia dice: sólo el Derecho positivo vincula; el pretendido Derecho natural no vincula. Y si está dispuesto a aceptar criterios o principios del Derecho positivo con tal que no sean ellos mismos Derecho, es porque cree que, eliminado este carácter, son inoperantes, inofensivos.

Ahora bien, es lógico negar que el Derecho natural sea Derecho, si se define la esencia de éste por ciertas determinaciones puramente formales: una regla o sistema de reglas (es decir, de enunciados en conceptos), originado en una autoridad exterior, perceptible, y dotado de coactividad. Pues el Derecho natural no las posee. Pero ello no alcanza para negar ni su ser ni su vinculatoriedad. Por consiguiente, la única consecuencia lógica sería la de privarlo de su nombre tradicional, puesto que éste contiene un elemento equívoco. ${ }^{21}$

Lo que constituye el núcleo central y permanente de todo el iusnaturalismo, si se mira más hondo que a las diversas fórmulas que ha acuñado en su historia, es que el Derecho natural no se determina por su forma sino por el contenido o los contenidos que lo sustentan: la naturaleza o esencia de las cosas en general (de los entes), del hombre, de la sociedad, de las relaciones que instauran los hombres entre sí y con las cosas. Conviene recordar a este respecto que Aristóteles $(N E 1134$ b 18 sigs.), uno de los puntales de todo el iusnaturalismo posterior, no empleó la nomenclatura "Derecho natural" y "Derecho positivo" sino "lo justo natural" y "lo justo legal". La distinción no opone dos sistemas de Derecho que pretenden regular las mismas relaciones, sino dos sectores de relaciones regulados el uno por la naturaleza y el otro por disposiciones originadas por la voluntad humana..22

Pero si el Derecho natural se define por su contenido mientras que el positivo se define por su forma, se sigue que, en principio, no puede haber una oposición necesaria entre ambos. Más bien son susceptibles de una alianza y de una interpenetración: si cada uno se mantiene en su esfera propia, habrá una alianza; si el positivo recoge en su forma los contenidos

21 Yo mismo he propuesto sustituirlo por el de "orden esencial" en Reflexiones sobre la justicia y el principio del derecho.

22 Cf. M. Salomon, Der Begriff der Gerechtigkeit bei Aristoteles, Leiden, 1937, págs. 48-68, a mi parecer, uno de los pocos que se aproxima a la comprensión correcta de la distinción aristotélica. 
del natural, habrá interpenetración. Es claro que la oposición es posible, pero sólo si cada uno traspasa los límites de su esfera propia, si el positivo recoge contenidos que divergen o se oponen a los del natural o si se pretende hacer pasar por Derecho natural lo que en su esencia queda abierto a las determinaciones del positivo. $\mathrm{Y}$ como esta situación se ha dado con frecuencia en toda la historia, la oposición (en sí no necesaria, pero posible) ha sido muchas veces real. $\mathrm{Y}$ es entonces cuando se planteará agudamente el problema de la vinculatoriedad, si bien, como veremos, éste trasciende a la mera situación de conflicto.

Ahora bien: no sólo no es exacto que únicamente el Derecho positivo vincule, sino tampoco que pueda justificar inmanentemente su vinculatoriedad.

La vinculatoriedad se funda en la validez que posee el Derecho. Pero respecto a éste hay que distinguir tres especies de validez: la formal-jurídica, la psíquica y la ideal.

La validez formal-juridica que puede llamarse también “juridicidad del Derecho",23 reside en que la génesis de una disposición o de un sistema de disposiciones jurídicas hasta su promulgación ha ocurrido en conformidad con otras disposiciones jurídicas cuyo contenido es, precisamente, regular en general la génesis de las disposiciones jurídicas. Así, las constituciones modernas regulan la génesis de las sentencias; ciertas leyes, la génesis de reglamentos o decretos. B. sólo conoce esta validez jurídico-formal. Pero su análisis queda a mitad de camino: se pregunta por la validez formal de un derecho respecto a la constitución, pero no se pregunta por la validez formal de la constitución misma. Y esta pregunta es pertinente porque la constitución es también Derecho positivo. Pero si se formula la pregunta, ella no puede encontrar a la larga respuesta satisfactoria dentro del Derecho positivo mismo, pues remontándonos hacia el pasado siempre se hallará un punto en que su génesis no ha ocurrido en conformidad con el propio Derecho positivo. El aserto de que "el Derecho contiene ante todo normas sobre sí mismo" (Brinz) sólo es verdadero para un trecho relativamente corto de la Edad Moderna, y aún dentro de él el Derecho se ha generado con frecuencia al margen y aún en contra de aquellas normas.

¿Y si el Derecho positivo mismo comcnzara por decretar (como efectivamente a veces lo hace o lo da a entender) como regla suprema la vinculatoriedad de sus disposiciones para aquéllos a quienes éstas van dirigidas? Pero este recurso sería, por un lado, insuficiente, por otro, superfluo, y, en total, no resolvería el problema. Insuficiente porque esa regla, al formar

23 Se le llama corrientemente "legalidad del derecho" o simplemente "legalidad", pero parece más correcto llamarla "juridicidad" porque la conformidad de una regla jurídica puede ser tal no sólo respecto a una ley, sino según los casos, respecto a un reglamento o a una constitución. 
parte del Derecho positivo, queda también sometida a la pregunta por la validez formal-jurídica, que, como se ha comprobado, se adentra en una senda cortada. Superfluo, porque el sentido de todo Derecho es vincular y, por consiguiente, esta determinación de su esencia no puede ser a la vez un contenido particular de aquél. De lo contrario, esa misma regla suprema que establece la vinculatoriedad debería fundarse en otra que estableciera la vinculatoriedad de la primera y así hasta el infinito. $Y$ no resolvería el problema porque aunque la vinculatoriedad pertenezca a la esencia del Derecho, ésta se da sólo como posible. y no como existente (real) y aun cuando se da como existente, la existencia de una obra humana, como es el Derecho positivo, no implica en sí misma su justificación.

La existencia de un Derecho no consiste en su mera validez jurídicoformal. Mientras quede en este punto sólo existe estrictamente para los que lo dictaron. Es preciso que sea conocido por aquéllos a quienes se dirige, esto es, por aquellos que tienen que cumplirlo o aplicarlo. Necesariamente tiene que devenir un objeto de su conciencia. Dejemos de lado ahora el problema de si el conocimiento sigue necesariamente a la promulgación (sobre el que habría algo que decir, así como sobre el "olvido" del Derecho). Pero aun cuando así fuera, ese conocimiento no basta para hacer del Derecho válido formalmente un Derecho existente. Para ello es necesario el asentimiento de la colectividad que es su destinataria. El es el que convierte a un Derecho con validez puramente formal en Derecho existente o vigente. El asentimiento no coincide, sin embargo, con el cumplimiento $\mathbf{u}$ obediencia. Ciertamente que no podría hablarse de un Derecho vigente si no fuera cumplido por una parte de sus destinatarios; por lo menos, por los que tienen que aplicarlo. El cumplimiento es la consecuencia fáctica común y corriente del asentimiento, y, desde luego, un signo de éste. Pero también el trasgresor del Derecho lo reconoce como vigente. El delincuente que huye, fabrica una coartada o extingue los rastros de su acción reconoce con ello la vigencia de la ley penal. El que oculta sus bienes en fraude de sus acreedores está afirmando su propiedad y el derecho de éstos a cobrarse en ellos.

El asentimiento no es, sin embargo, el contenido de una decisión plenamente consciente, sino una vivencia más bien pasiva que activa, que puede tener origenes muy diversos (y que pueden confluir entre sí) como el temor, la imitación, la propaganda, el interés, pero también el sentimiento del valor positivo o de la razonabilidad del derecho dictado. Es a ese asentimiento al que llamamos "validez psíquica" y también "vigencia" del Derecho. Sólo la vigencia dèl Derecho constituye a la vinculatoriedad como real y no como simplemente escrita en un pedazo de papel, porque sólo el Derecho vigente es el derecho existente en una colectividad.

Pero el asentimiento, cabalmente porque es una vivencia que puede 
obedecer a las más diversas motivaciones, no es una dimensión fija e invariable. Su estabilidad puede ser más o menos larga, pero puede también oscilar o llegar a extinguirse en todo o en parte. Por eso la validez psíquicosocial no coincide necesariamente con la validez formal-jurídica.

De todo este fenómeno de la validez psíquico-social del derecho $B$. nada sabe y reduce la existencia del Derecho positivo a su carácter de "energía activa" contra la cual el hombre chocaría siempre. Aunque B. no analiza ni aclara en qué consiste esa energía activa, es evidente que este concepto es un eufemismo para significar la coacción propia del Derecho. Dicho sin ambages: el Derecho es existente o real como fuerza organizada por el Estado. Ésta es la última ratio que, expresa o tácitamente, implica todo positivismo jurfdico. $\mathrm{Y}$ sin embargo, esta ratio no puede ser la última no ya filosóficamente, como luego se verá, sino ni siquiera en el terreno de los hechos. Porque es evidente que el Derecho en cuanto regla no posee ninguna fuerza. La fuerza se la concede el grupo de hombres encargado de su aplicación al resto de la colectividad. Y para ello es necesario que ese grupo de hombres, por lo menos, asienta a las reglas que ellos mismos tienen que aplicar. La propia fuerza organizada no puede funcionar, pues, sino sobre la base de cierta validez psíquica. Pero hay más: la coacción es eficaz porque de hecho sólo se emplea contra los transgresores cuando son una parte relativamente pequeña de la colectividad. Si ésta en su conjunto o en su mayoria se convierte en transgresora, la coacción se torna impotente, como lo hemos visto en el Satyagraha de Gandhi para liberar a la India de los ingleses. Por consiguiente, la misma coacción supone que la colectividad en su término medio ha reconocido el Derecho. $\mathrm{Y}$ he aquí cómo un "pensamiento en la conciencia" no es menos sino más que la "energía activa" de la coacción estatal. La vinculatoriedad efectiva se asienta en la validez psíquico-social y no meramente en la formal-jurídica.

Pero queda aún la cuestión decisiva. B. sostiene no sólo que el Derecho es una energía activa, sino también que basta éste su carácter existente para justificarlo. Ahora bien, esta afirmación es errónea. Ya hemos dicho antes que el Derecho positivo es una obra humana, y que una obra humana por el hecho de existir no lleva en sí su justificación. Toda obra humana es como es, pero podría ser de otro modo; es, por consiguiente, susceptible de ser juzgada, apreciada, y el rasero de su apreciación son los valores que por su sentido ella encarna o pretende encarnar. Esos valores pueden ser de especie y grado diversos, y quizá una obra sólo puede justificarse si responde a un complejo de valores diversos. Así, por ejemplo una obra arquitectónica tiene que responder a la vez a valores de seguridad, de utilidad, de comodidad, de belleza, etc.

Es claro, pues, que interrogarse por la justificación de una obra significa interrogarse por su conformidad o disconformidad con un rasero (o 
patrón) a priori respecto a la obra misma. $\mathrm{Y}$ es claro también que la pregunta por la justificación sólo es legítima respecto a lo que es resultado de la libertad, y que no tendría ningún sentido respecto a los hechos de la naturaleza, como por ejemplo preguntar si se justifica que existan el agua o el hierro en el mundo físico.

$\mathrm{Y}$ respecto al Derecho positivo la pregunta por su justifcación es más apremiante que respecto a las demás obras humanas en virtud de su carácter vinculatorio. El hombre sometido a un determinado Derecho positivo podrá siempre preguntarse: '¿por qué estoy obligado a cumplir sus preceptos?' $\mathbf{Y}$ también el hombre o grupo de hombres que dicta el Derecho podrá preguntarse: '¿por qué ha de obligar a los demás (y a nosotros mismos) el Derecho que hemos dictado?'

Ciertamente que el sentido de todo Derecho es vincular, pero el problema no es ahora el comprobarlo sino el inquirir su porqué. $\mathrm{E}$ inquirir su porqué significa hallar la razón o fundamento de su vinculatoriedad. Esta razón o fundamento es lo que antes hemos llamado la "validez ideal".

Es evidente que la validez formal-jurfdica y la "energla activa" del Derecho no suministran la respuesta a nuestro problema, puesto que son cabalmente ellas las que lo hacen surgir. Ya sabemos que esa "energía activa" tiene un nombre más conocido que es "la fuerza o coacción del Estado". Yo sé que contra ella no puedo y que de ordinario tendré que someterme. Pero des ella la que "justifica" al Derecho, su vinculatoriedad, mi obligación? ¿No es precisamente esa fuerza la que requiere una justificación para ser distinguida de una fuerza no justificable? Y si como Michael Kohlhaas, aunque con menos derecho que él, yo lograra concentrar una fuerza colectiva superior a la del poder público y la venciera, ¿estaría, entonces, lo que yo dictara, justificado como Derecho?

Pero tampoco suministra respuesta a nuestro problema la validez psíquica, como una consideración superficial podría sugerirlo. Pues el asentimiento es también un hecho, un hecho psíquico, inestable, oscilante, extinguible y que, además, puede obedecer a las más variadas motivaciones, la mayoría de ellas irracionales. En cambio, preguntarse por la justificación, razón o fundamento de la vinculatoriedad del Derecho entraña buscar una razón objetiva, válida en sí misma, independiente de los hechos empíricos, que se presente como tal a una conciencia clara y reflexiva, esto es, a una conciencia filosófica. Y hallado tal fundamento, él vinculará a la conciencia con una fuerza más eficaz que la fuerza del Derecho positivo.

Estas explicaciones hacen patente que el problema de la justificación del Derecho positivo, lejos de ser superfluo, como quiere B., es un problema auténtico que necesariamente ha de plantearse.

$\mathrm{Y}$ es cabalmente porque hay tal problema, que la doctrina del Derecho natural intenta una solución al mismo. 
Conducido por su errónea tesis (que criticamos más arriba) de que tanto el Derecho natural como el positivo son sistemas cerrados, sin lagunas, B. no concibe ahora la relación entre ambos más que como una alternativa de dos miembros:

O el Derecho natural no concuerda con el positivo, en cuyo caso se convierte en rasero crítico de éste y es esgrimido contra su vinculatoriedad total o parcial; o el Derecho natural coincide con el positivo, en cuyo caso se presenta como fundamento de éste, pero al mismo tiempo como inútil e insuficiente.

B. no ve que hay una tercera posibilidad: que el Derecho positivo contenga cantidad de preceptos que ni discrepan ni coinciden con el Derecho natural, sino que trascienden la esfera de sus principios. $Y$ ésta es precisaménte la doctrina de la escuela clásica desde Aristóteles, pasando por Santo Tomás, hasta los protestantes de la Edad Moderna, con excepción de Wolff y de su escuela. Pero la vinculatoriedad de estos preceptos era fundamentada por los clásicos indirectamente en el propio Derecho natural, ya sosteniendo que son derivados de éste como "conclusiones" o como "determinaciones" y que éstas obligan en conciencia cuando son justas (entendiendo por tales no sólo las que se ordenan al bien común sino también por el sólo hecho de ser dictadas por una autoridad dentro de los limites de su competencia) (Santo Tomás); ya sosteniendo que todo el Derecho positivo se basa en un pacto (no importa para este efecto si se trata de un pactum unionis o subjectionis) y que es un principio del mismo Derecho natural el cumplir los pactos (pacta sunt servanda) (Grocio, Hobbes, etc.). Se intentaba así una justificación suprapositiva de la vinculatoriedad de las leyes porque se veía que éstas no la tienen de por sí.

Veamos ahora los dos casos que contempla $\mathbf{B}$.

Respecto a la inutilidad del Derecho natural como fundamento del positivo cuando ambos coinciden, hay que comenzar por advertir que es un abuso de lenguaje decir que es el natural el que concuerda con el positivo (como si aquél fuera una invención posterior), cuando la verdadera relación es la inversa: son ciertas disposiciones del positivo las que coinciden con principios del natural. Bien lo habia visto Grocio cuando destacaba que un principio no es de derecho humano porque la ley positiva lo formule, sino que a veces sólo "expresa" lo que es de Derecho natural.24 Y la concordancia se explica fácilmente, porque los legisladores han debido necesariamente inspirarse en sus principios para dictar sus leyes. Esto es evidente sobre todo en el Derecho privado: el derecho a conservar y defender la propia vida, el derecho a contraer matrimonio, al trabajo, la obligación de mantener y educar a los hijos menores, de cumplir los contratos, de someter los litigios a un juez o a un árbitro. Piénsese lo que sería una

24 De jure belli ac pacis, II, II, 6, 3. 
legislación que intentara desconocerlos, por ejemplo imponiendo el celibato universal, prohibiendo la defensa de la vida o concluir contratos, etc. La cosa es tan absurda que parece una simpleza mencionarla. Y sin embargo, en la esfera jurídica, como en todo el ámbito del conocimiento humano, los principios que parecen más triviales son los más importantes, los más fecundos en consecuencias.

De este modo se hace patente que los principios del Dêrecho natural son los que constituyen el fundamento justificador de la vinculatoriedad del Derecho positivo. Pues si el hombre sometido a sus dictados se formula la pregunta '¿por qué estoy obligado a cumplirlos?' y conoce que ellos coinciden o derivan de principios del Derecho natural o, como decimos brevemente, que son justos, porque se fundan en la naturaleza de las cosas, en la del hombre mismo y en los valores que ellos encarnan, habrá encontrado un fundamento de validez último, que satisface a la conciencia reflexiva, como no podría satisfacerla un fundamento que consistiera en la mera existencia de hecho o en la "energía activa" del Derecho positivo, que el hombre tendría que obedecer, sí, pero no por convicción sino para no romperse la cabeza y el alma contra la coacción del Estado. Es claro que en cualquiera de los dos casos el individuo podrá siempre hallar algún resquicio para transgredir el Derecho. Pero si ese Derecho se funda en el Derecho natural, no podrá justificarse alegando que se rebela contra la arbitrariedad. Será un simple transgresor.

La objeción de $B$. de que habría que buscar también el fundamento de la vinculatoriedad del propio Derecho natural no es válida. El Derecho positivo requiere esa justificación porque es obra humana, y puede tener este o aquel contenido. Pero lo que se funda en la esencia y en el valor intrínseco de los entes tiene en éstos su razón de obligar.

Finalmente, después de estas consideraciones, será fácil tomar posición frente a la crítica del Derecho natural en cuanto se presenta como rasero crítico del positivo. B. tiene razón en pedir al jurista que refrene las convicciones o deseos de su corazón y espere la oportunidad para reformar el Derecho. Pero el Derecho natural no se identifica con convicciones ni deseos individuales que anhelan simplemente mejorar el Derecho. No tenemos que discutir aquí cuáles son las fuentes del Derecho natural, porque ese es tema de otro capítulo de la obra de B., que se examinará en la segunda parte de este estudio. Ahora sólo hemos de examinar la cuestión de sus consecuencias, que es la que encara $B$.

$Y$ bien: si existen principios de Derecho natural y se da un Derecho positivo, algunos de cuyos preceptos se oponen a aquéllos, de acuerdo con todo lo que hemos dicho anteriormente hay que concluir que tales preceptos carecen de validez ideal y muy probablemente carecerán de validez psíquico-social (si los sujetos advierten la existencia de aquellos principios), 
esto es, que no serán vinculatorios para la conciencia. Es claro que el Derecho positivo conservará su vinculatoriedad formal, pero hemos visto que ésta no consiste más que en la coacción del Estado. Aún así será necesario que jueces y funcionarios administrativos encargados de aplicarlos asientan a esos preceptos, porque si esto también falla, por más que el positivismo juridico clame y proclame que "hay que afirmar incondicionalmente la validez del Derecho positivo" ésta se disipará como la niebla matutina con el calor del sol.

Sin embargo, que el Derecho positivo contrario al natural no sea obligatorio para la conciencia, no debe conducir a su desconocimiento puro y simple. Puede ser que haya razones que induzcan a la obediencia, por ejemplo, si de la actitud contraria ha de seguirse un mal mayor para la comunidad. Por lo demás, hay una gradación en las actitudes contra tal derecho: desobediencia pasiva individual o colectiva, o transgresión violenta individual o revolución. El que se adentra por esa vía con buena conciencia no es entonces un transgresor sino un quebrantador del Derecho injusto.

Por eso, cuando B. nos dice que el Derecho natural contiene "tendencias de agitación", no podemos menos de asentir a ello y añadir que tal proposición se queda corta, pues hay también un Derecho natural a la revolución, la cual en ciertos casos extremos puede ser incluso un deber. Pero cuando B. califica al Derecho natural de "ficción vacía" y niega que sea Derecho, sucumbe a la ilusión de creer que así lo hace inofensivo y que el Derecho positivo mantendrá incólume su vinculatoriedad. Entretanto, hay principios no juridicos (positivos) que vinculan a la conciencia más estrechamente que los jurídicos y pueden convertirse en una fuerza derrocadora del Derecho. La historia bien nos ha enseñado ya varias veces cómo la "energía activa" de las leyes puede tornarse ficción y cómo la "ficción" de aquellos principios puede operar como energía activa.

La última ratio que esgrime aquí $B$. es que tal Derecho natural conduciría a la destrucción de todo orden jurídico, a la anarquía. A lo cual con rigor lógico habría que responder que vale la pena correr el riesgo cuando la sacralización del Derecho positivo ha conducido, a su vez, a la tiranía - a una situación de grave injusticia muy generalizada. Pues la historia también enseña que las naciones han podido superar mucho más rápida. mente los estados anárquicos que los tiránicos.

Pero la consecuencia que extrae B. no es forzosa. Ya hemos visto que el Derecho positivo que contraviene al natural no ha de conducir necesariamente a su desobediencia, y que donde ésta tiene lugar, puede ocurrir en modos y grados en los que sería una exageración hablar de destrucción total del orden jurídico o de anarquía. Muchas veces se tratará de una sola ley, quizá sólo de algunas de sus disposiciones, cuyo incumplimiento 
producirá, sin duda, un desorden desde el punto de vista de la validez formal, pero que estará muy lejos de causar la anarquía. La amenaza con ésta es, por lo general, sólo el "coco con que pretende amedrentar todo conservadurismo a ultranza.

En conclusión, pues, ninguno de los argumentos invocados por B. contra el Derecho natural en su relación con el positivo me parece concluyente.

En un segundo artículo examinaremos sus críticas al Derecho natural por su relación con el concepto del Derecho.

Juan Llambías de Azevedo 